\title{
Shame, stigma and the take-up of social assistance: Insights from rural China
}

\author{
Mianguan Li ${ }^{1}$, Robert Walker ${ }^{2}$ \\ ${ }^{1}$ Department of Law and Political Sciences, Zhejiang Normal University, PR. China \\ ${ }^{2}$ Department of Social Policy and Intervention, University of Oxford, United Kingdom
}

Forthcoming in the International Journal of Social Welfare

\begin{abstract}
While the reasons for low take-up of social assistance benefits are complex, stigma is understood to be an important factor. In this study, the proposition that financial need and social rights moderate the deterrent effect of stigma was examined with respect to China as a deviant case. Dibao, the world's largest social assistance scheme, is characterised by high take-up but poor targeting, stigma and informal discretion in the context of rapidly declining poverty. Qualitative fieldwork reveals how the contrasting stigmas of poverty and abuse are negotiated to claim benefits and illustrates the dangers of implementing social assistance without supportive political, legal and cultural infrastructures.
\end{abstract}

\section{Key Practitioner Message:}

1. Dibao, the world's largest social assistance scheme, is characterised by high take-up but poor targeting.

2. The weakening of shame associated with injustice helps to account for the large number of ineligible people successfully claiming dibao.

3. The strengthening of shame linked to poverty helps to explain the low take-up of dibao by people experiencing poverty.

Keywords:

dibao, shame, stigma, take-up, social assistance, rural China

Correspondence to:

Mianguan Li

Department of Law and Political Sciences

Zhejiang Normal University

NO. 688, Yingbin Street, Jinhua City, Zhejiang Province

PR. China, 321004

E-mail: limianguan@126.com 


\section{Introduction}

Stigma is frequently found to be an important factor in the low take-up of social assistance (Finn \& Goodship, 2014; Hernanz, Malherbert, \& Pellizzari, 2004). The causes of this stigma are complex: personal, social and institutional, part instrumental, part normative (Baumberg, Bell, \& Gaffney, 2012). Social norms, ubiquitous across cultures, conspire to link reliance on state benefits with notions of failure, personal weakness and abuse: such norms include the work ethic, the reciprocity inherent in social relations, obligations personally to care for dependents and expectations of individual self-reliance. These normative expectations are habitually adopted by individual members of society as their own code of behaviour, causing benefit recipients to feel a sense of personal stigma. Furthermore, this code is frequently deliberately reinforced through institutional stigma in the framing, structure and delivery of benefits, often with the normative goal of rewarding socially desirable behaviour but also instrumentally to deter abuse, stem demand and minimise cost (Baumberg, 2016; Gubrium, Pellissery, \& Lødemel, 2013). Hence, benefits tied to reciprocity, an exemplary work record or contributions are generally less stigmatised than social assistance based on need (Oorschot, 2006). Stigma is inherently divisive, separating the desirable from the undesirable, and may differ in this respect from shame, the threat of which is sometimes interpreted as a means of establishing shared norms and fostering social cohesion (Walker, 2014). Whether people subjected to stigma and shaming would recognise this subtle distinction is a moot point; the evidence is that both stigma and shame are experienced as being personally hurtful and demoralising. Confronted by the decision whether or not to claim benefits, the internal feelings of stigma or shame serve to erode agency and self-image for, as Lister (2004, p. 119) noted, 'shame and humiliation peel away self-esteem' .

Need and recourse to rights have been posited as antidotes to stigma in the decision to apply for social assistance (Kerr, 1982; Lister, 2004; Ritchie, 1988). It was once simply assumed that people in extreme need had no choice but to claim benefits (Lister, 2004).

However, it is now appreciated that, while choice sets may be severely constrained, people in poverty typically exploit a range of material and other resources purposively and creatively to respond to life circumstances (Leisering \& Leibfried, 1999; Lister, 2004). Hence, applying for social assistance is perhaps best construed as an active choice in which the stigma attached to claiming is an important consideration (Daigneault, Jacob, \& Tereraho, 2012). From the perspective of the rational economic actor, the benefits of claiming are seen to outweigh the negative assessment of the self in admitting the failure to sustain self-sufficiency (Dorsett \& Heady, 1991; Jordan, 1996). But the claimant also needs to negotiate social stigma, avoiding others' negative evaluation which may require a second layer of self-justification. For example, in certain cultural contexts families prioritise children's future above everything else and therefore applying for social assistance in the name of the children's development, such as education, health or appropriate clothing, may to be considered socially acceptable (Ridge, 2002).

The second perspective, based on social rights, addresses stigma by redefining social assistance recipients as 'legitimate claimants of entitlements' rather than as 'beneficiaries of government largesse' (Lister, 2004, p. 162). What might have been ethical or moral claims on 
state resources become the duties of government and society (Ferguson, 1999; Pogge, 2002; Sen, 1999) and, hence, it is expected that people who claim benefits are exerting their right as citizens to do so. In such a scenario, one would anticipate stigma to be much reduced and benefit take-up to be high. While both perspectives are analytically separable, in practice they need to be interpreted together as many people claim and express their basic needs through the approach of social rights. Nevertheless, one might expect take-up to be highest when material need is great and claiming is legitimated through recourse to social rights.

This line of reasoning is consistent with experience in developed welfare states, but may not hold elsewhere. The shame of poverty and the stigma associated with social assistance is arguably much reduced when extreme poverty is ubiquitous and persons in poverty are not held to be individually responsible for their plight (Jo, 2013). Often, too, the rhetoric of human and social rights found in constitutions and legal provisions is not matched in the implementation of policy and/or in the normative collective understanding of daily life and social relations. China is a case in point. It boasts the largest social assistance system in the world - dibao - for which demand is high with total expenditures in 2009 equating to 64\% of the ex-ante poverty gap (Golan, Sicular, \& Umapathi, 2014). Moreover, while dibao is nominally rights-based, support for individual human rights is largely absent from state political discourse and not widely demanded in a society more attached to collective ideas than to individualism. Furthermore, although poverty remains high, it has been falling at a globally unprecedented rate, coincident with a political re-framing of poverty as individual failure rather than the product of capitalist exploitation (Walker, 2014). Poverty is therefore now stigmatised rather than being considered structural, but such stigma has failed to deter the ineligible from claiming. Indeed, some $86 \%$ of people receiving dibao are thought to be ineligible, while just $11 \%$ of those who are eligible for dibao receive it.

\section{Table 1 here}

The extremely poor targeting of dibao has been officially recognised (Zhu, 2012) and attributed to 'unhealthy practices' elaborated to include poor local administration and inadequate staff, a lack of transparency, and corruption with staff directing dibao to relatives and friends, a criticism commonly aired in regional newspapers (Golan et al., 2014). These 'unhealthy practices' have, in turn, been linked to the abuse of local flexibility that was deliberately designed into dibao in order to accommodate the vast variation in circumstances and administrative infrastructures that especially characterise rural China. Others have offered structural explanations for the ineffective targeting, documenting the ways in which dibao has been co-opted as a tool of local governance and used to build political support and to stem social unrest, with various tiers of government being complicit in this process (Li \& Walker, 2016). However, no one has reflected on the perverse targeting of dibao through the lenses of shame and stigma. In doing so, our aim is to better understand how the extreme targeting of dibao is sustained through the attitudes and behaviour of potential applicants. A further aim is that, by examining China as a deviant case, to investigate the limits to the aforementioned propositions that need and rights moderate the effects of stigma as a deterrent to claiming social assistance (Seawright \& Gerring, 2008)

\section{Method}


The research site, renamed as Stone-bridge by the authors, is a small village located in south-central China. It was chosen because it shares many characteristics typical of villages in central and western China. First, it is remote, lying far from the regional political and economic centre. There is no public bus service connecting village and town, and the most common mode of transport is the private farm vehicle which, however, is prohibited by law to carry passengers. Remoteness means that the village committee can implement national social policies without close supervision by higher authorities. Secondly, little collectivist production remains from the Maoist era, which means that most families depend for income on small-scale agriculture and remittances from migrant workers. The resultant limited and unstable family incomes serve, in turn, to emphasise the importance of social policy and access to the resources of dibao. For the village committee, with little ability to build and reward political support through the allocation of income from collective production, dibao offers an alternative means of fostering community allegiance.

At the end of 2014, the population of Stone-bridge was around 2,500 persons (700 families) and was organised into a dozen quasi-administrative villagers' groups (to maintain confidentiality, the statistics presented are rounded). According to the report submitted to the town government by the village committee, household per capita annual income in Stone-bridge averaged around 3,500 yuan RMB (about \$570) in 2014, meaning that if one could get the resource from dibao, the benefit would correspond to more than one-third of one's annual income. Evidence for this article was based on semi-structured interviews conducted by the first author with 46 villagers and six members of the village committee using a mix of face-to-face and telephone interviews. All the interviews were conducted after implementation of the 2013 reform, with the face-to-face interviews being undertaken in July and August 2014 and in January 2015, and the telephone interviews in August and September in 2015. Systematic snowball sampling was employed and yielded a group for interview comprising 29 women and 23 men with an age range from 27 to 69. Twenty-three respondents were recipients or former recipients of dibao. Thirty-four respondents were only interviewed face-to-face, seven were interviewed twice using both methods and 11 were interviewed solely by telephone.

The phenomenon of interest lends itself to qualitative research: a village-based decision-making process involving complex interactions between different policy actors including members of the villagers' committee, dibao recipients and non-recipients of social assistance, called upon vouch for dibao applicants (Merriam, 2014). Through long-term engagement with the village, combined with the flexibility of semi-structured interviews, the lead author established a level of trust with respondents that enabled him to not only ascertain their attitudes, behaviours and motivations, but also elicit their accounts and opinions of other policy actors and explore their reasoning and rationales. A diachronic perspective was adopted with respondents encouraged to compare eras pre and post the introduction of dibao.

While qualitative research prioritises depth over generalisability, the sampling method sought to reduce the bias inherent in snowball sampling by first choosing one person at random to interview, then a person that the respondent identified as being likely to receive dibao and then that person's neighbour. The validity of the research was further enhanced by conducting all interviews in the local dialect, translated into Mandarin Chinese for analysis. Open coding was undertaken initially with codes subsequently being grouped thematically, 
with selected verbatim passages only later being translated into English (Ritchie, Lewis, McNaughton Nicholls, \& Ormston, 2014).

\section{The puzzle}

To restate the puzzle, China represents an exceptional case of great demand for social assistance in a context where a rights discourse is largely absent and, although still high, poverty rates have been falling rapidly. A further enigma is that dibao is received by many people ineligible to receive it.

Dibao was first introduced in Shanghai in 1993 and by 1999 had been adopted by all other cities. Expansion into rural areas was slower and not complete until after dibao was consolidated as a national scheme in 2007 (Li, 2012; Wu, 2009). Dibao has many of the characteristics of a traditional social assistance system, with cash benefits used to bring recipients' income up to a determined threshold, albeit with a means-test applied to the extended family rather than to the household. Although a national scheme, benefit thresholds are fixed by counties while applications are processed under the auspices of village committees comprised of elected representatives (cadre), leading to recommendations for payment being made to counties. In 2014, over 52 million people were supported by rural dibao.

Assessment of rural incomes is notoriously difficult and in administrating dibao documentary evidence is often replaced by neighbourhood knowledge. The names of persons applying for dibao are posted publically and objections elicited from neighbours and others. The role of elected cadre and the non-documentary nature of assessment have been cited as reasons for poor targeting, and there are multiple reports of village cadres completing applications for relatives and friends (Cui, Liu, \& Song, 2009; Li \& Li, 2015; Zhu, 2011). It was in response to this kind of evidence that the reform implemented in 2013 sought to make dibao more regulated and transparent with a reduced role for village cadre.

The administration of dibao in the village of Stone-bridge reflects the national picture. The county government set the eligibility threshold at 1,600 yuan RMB per capita per year (about US\$260), meaning that anyone with an income below this figure should receive the difference in dibao. In practice, as frequently happens elsewhere, formal means-tests are not conducted; instead the village committee relies on local knowledge and public scrutiny:

Interviewer: Do you think it is necessary to make means-tests in the village?

Respondent: I don't think so. The village is so small and villagers are so familiar with each other that villagers even know how many chicks their neighbours have. We... believe that publicity is reliable. (Li X., senior member of the village committee)

Another consideration is that the town government, a street-level administration which functions as the executor and supervisor, imposes a ceiling on the number of awards that can be made by the village, which takes priority over the threshold. Furthermore, the demand far exceeds the ceiling figure:

It makes me dizzy that there are so many people applying for dibao every year. The town government told us that only 215 persons in our village could get the benefit this year, and we have told villagers the truth. (Li Q.H. leader of the village committee, male, 51 
years old)

What this makes clear is that there is no definitive eligibility threshold to discriminate between eligible and ineligible, which, of course, also serves as a healthy warning with respect to the veracity of the statistical analysis of targeting reported above. It also makes it very difficult to establish the extent, if not the existence, of mis-targeting in the village. Nevertheless, local knowledge, as revealed in the interviews, was strongly of the opinion that dibao was being received by at least some people who were ineligible:

I really think Tang [a recipient] should not get the benefit, as her son has a formal job in town government and gives her money monthly. Her house is the most beautiful one among us. If I had a condition like hers, I would not take the money even if the village cadre gave it to me. (Li M.C., villager, male, 46 years old)

Some people are really poor but cannot get the benefit, and some people are not poor but get the benefit. It is unfair to all. (Wu M., villager, female, 42 years old)

Moreover, members of the village cadre were quite prepared to admit that they chose to allocate dibao to people who were ineligible on grounds of need. They did this mostly for reasons to do with governance - to build support for the committee, to foster good behaviour within the community, to deter anti-social behaviour and to curtail dissent - but they also admitted that sometimes they felt obligated to recommend dibao to be paid to their relatives (Li \& Walker, 2016).

\section{Shame, poverty and injustice}

If, as indicated, Stone-bridge is a microcosm of the delivery of dibao in rural China, what can be learned about the role and construction of stigma in explaining excessive demand and defective targeting? This question is best addressed by distinguishing people who are potentially eligible from those who know themselves to be ineligible. For people in poverty and potentially eligible for dibao, the most important deterrent to claiming appeared to be the shame or stigma associated with poverty, whereas those who were knowingly ineligible but nevertheless claimed benefits needed to negotiate the risk of opprobrium associated with illicit behaviour, the shame of injustice. Social and political changes have differentially affected the salience of these two forms of shame, intensifying that associated with poverty but weakening that linked to injustice (Figure 1).

\section{Overcoming the stigma and shame of poverty}

\section{Figure 1 here}

For most villagers, to be poor is shameful and to be evaluated as poor by neighbours deepens that sense of shame. Applying for dibao entails public exposure on two separate occasions: first, following submission of an application to a villagers' group that discusses their case in public, and then again after the town government responds to the village and candidates have to be evaluated by villagers for the second time. Such stigmatising procedures are sufficient to deter some people from applying for dibao:

Although I am poor, I would not like others to say that I am poor. You know, it is not a good reputation. If I apply for [dibao], it means that I cannot feed my family and myself. 
What would people think of me? One of my neighbours applied for it once, and many people commented on his income and behaviour. ... It is not worth it. I would not want to apply because I don't like others laughing at my daughter and me. (Li J.P., villager, female, 45 years old)

But, as would be predicted by the basic needs hypothesis, some people have needs so severe that they are prepared to confront the stigma. For those applicants who are refused dibao, public denigration adds to the shame of poverty, but some keep trying, hoping that one day assistance will be forthcoming.

Even though dibao makes me feel uncomfortable, I must apply because I have no choice. I have only one hand now and I can't do any heavy work. Most of my neighbours know my situation, that I cannot feed myself. (Hu J., villager, male, 43 years old)

I have to apply for dibao. Although I did not get it this year, I will apply for it next year. You see, my husband has become disabled and cannot earn ... I know that dibao is limited, and it would be not a huge help even I did get it, but it is better than nothing. (Wu M., villager, female, 42 years old)

\section{Negotiating the shame of abuse and injustice}

The shame attached to poverty might be expected to deter applications from people who are ineligible; indeed, that is arguably the social and political function of the stigma associated with social assistance and this was occasionally observed in Stone-bridge:

I would not like to apply for dibao because I don't need it and it's really shameful.

Actually, our family is not poor because my son and daughter give me about 800 yuan

$R M B$ every month. It is enough for my daily needs. If I received dibao, what would others think? They would say our family is poor or they would say my son and daughter failed to fulfil their moral obligation to look after me. Both would bring shame to my family. (Li S.E., villager, female, 61 years old)

Others, however, ignored the shame associated with poverty because they knew they were not poor:

When I decided to apply for dibao, I imagined what others would say. Villagers would discuss whether I was poor, but I did not care that much ... Even if others say I am poor, their words will not suddenly make my family poor. (Li J.M., villager, male, 52 years old)

However, most of those applying for dibao who knew that they were ineligible had additionally mentally to negotiate the guilt of behaving illicitly and having the potential shame of this injustice being exposed:

Frankly speaking, I struggled with myself when I decided to apply for dibao. My son has

a formal job in the town government, and he gives us money every month. You know, I am not very poor from the perspective of the quality of my house or our income ... I worried that others would think that it is unfair if I got the benefit because others are much poorer than me. I finally applied because my husband and village cadres all encouraged me to do so. (Tang L.G., villager, female, 63 years old) 
The most important thing is gossip. If they think I am not poor and should not get the benefit, they should have reported it when I applied for dibao, but they didn't. When I receive the benefit, they always talk about me behind my back..., I have to think about this kind of gossip every year when I decide whether to apply for dibao. (Liu Z.R., villager, male, 37 years old)

Nationally, if the statistics are anywhere near correct, very large numbers of applicants negotiate both the guilt of defrauding the system and the shame associated with injustice and poverty. They may be helped in this by the ambivalent attitudes of members of the village cadre who wish to be seen as acting justly, but who acknowledge merit in using dibao for purposes other than poverty relief:

We would like to be fair, and we would like to try our best to guarantee justice. Justice is an abstract word, while actual front-line work is quite complex. I think that the best way to guarantee justice is to make it public. Everyone can apply for it and everyone can express his/her comment on other applicants. Of course, the village committee will confer and decide on the list of candidates. I know some villagers say that there are many people who are not poor but get dibao and they think that it is unfair. But in my opinion, justice is a relative matter. One thing could be fair when estimated from one aspect, while it could be unfair when assessed differently. (Li Q.H., leader of the village committee, male, 51 years old)

\section{Understanding the mis-targeting of dibao}

Reflecting on why dibao fails to reach the people intended, it is helpful to consider the moral reasoning, first of ineligible applicants, and then of those who are eligible but do not receive it.

\section{Rewarding the ineligible}

In seeking to explain the large numbers of ineligible people applying for and receiving dibao, it is necessary to reflect on the legacy of Confucianism and on the way in which ideas have been accommodated and indeed co-opted by the communist system. Bedford and Hwang (2003, p. 131) neatly encapsulated the differences between Confucianism and Western culture by pointing out that 'Western individualism is premised on the conception of personal rights, rather than personal duties or social goals. In contrast, Confucian ethics are based on concepts of personal duties and social goals rather than on personal rights.' In China, a unique form of social relationship, chaxugeju, has come into being through which these personal duties have been facilitated and enforced. Strongest in rural areas, chaxugeju describes a system in which each person or family is located at the core of egocentric networks of social relationships in which the strength of obligations and responsibilities is greatest at the core and declines with distance from it (Fei, 1992). The net balance of obligation between individuals and groups of individuals effectively creates as social currency, guanxi, which can be employed to solve individual and social problems and in effect substitute for the formal rules, laws and policies that govern Western societies. This traditional system has persisted under communism with a 
difference evident between 'close comradeship' and 'common comradeship', the former being akin to clientelism or nepotism (Vogel, 1965). Thus, when the family-based production and distribution system was replaced by a collective regime, the village cadres and leaders often privatised public resources and distributed them to their relatives and friends in accordance with their obligations under chaxugeju (Qi, 1985; Sun, 1996). Moreover, with marketisation and the dismantling of collectivist production, there has been 'a re-emergence of certain traditional patterns' of chaxugeju (Gold, 1985). In the context of dibao, local cadres are necessarily compromised because their obligations to family and friends under chaxujeju override their responsibilities under an alien bureaucratic system (Geng, 2012; Li \&Li, 2015; Liu, 2009). While the communist authorities have instigated various purges against chaxujeju manifest as 'corruption', they have often been complicit in exploiting chaxujeju as a governance tool useful in maintaining stability and controlling political unrest (Li \& Walker, 2016).

The administrative ambivalence towards the needs-based rationale for dibao certainly lessens the guilt attached to abusing the system and reduces the likelihood of such behaviour being considered shameful or, indeed, punishable. Moreover, the multiple purposes for which dibao is used by village cadres has removed the direct link between dibao and poverty such that some villagers may not even appreciate that dibao is intended solely to benefit people in poverty. This misperception may arise inadvertently as a consequence of the way that dibao is used by the village cadres, but equally it is for them a convenient signal that, in the right circumstances, dibao may be available to people who are not poor.

Many people who are not poor get dibao. This situation has continued for several years here. Many applicants think that dibao is not solely for the poor but for others too. I applied for it although I am not the poorest in our village. Other people who don't get dibao hate us, but we who do don't laugh at each other. (Li M.J., villager, male, 41 years old)

Insofar as dibao is used by the village cadre to fulfil their responsibilities or to create obligations under the 'chaxugeju' system, for example in order to secure the political support of other influential villagers, receipt of dibao may come to be viewed as indicative of both a favoured status and as an expression of their own high 'guanxi'. This may, in turn, attract applications from people eager to enhance and/or to display their social status:

My uncle is Li Q.H. He is a main leader of the village committee. I asked him whether I should apply for dibao, and he told me to apply for it and said he would say something favourable for me to other village cadres. And then, I got the benefit of dibao. I do not think everyone in our village has the same chance to get dibao... Some of my neighbours say that I am so lucky because I have a helpful uncle. (Li M.H., villager, male, 34 years old)

A further reason why some people who apply for dibao when they are not poor are little troubled by guilt or any sense of shame is a legacy of the long history of collectivism that characterised rural China before marketisation. During that era, government controlled most of the resources, the collectives were reliant on the government, and villagers depended on the collectives and hence indirectly on a government that effectively controlled their life. 
Although the structure of society has changed, some see dibao to be theirs, not by right, but simply because in the collectivist era everyone had an equal chance of receiving government support.

Why did I apply? The most important reason is that dibao comes from the government, and it is my loss if I don't apply for it. (Jiang J.X., villager, female, 54 years old)

Dibao...Many villagers think that government resources should be distributed to everyone, and they take it for granted. (Xi X.H., senior member of the village committee, female, 49 years old)

\section{Deterring the eligible}

While dibao is claimed by many people who are ineligible, the vast majority of the target group receive no benefit. Some of the latter believe that their poverty is accompanied by a lack of 'guanxi' which makes application futile.

It is my destiny to be poor. Village cadres have their own relatives and I have no relationship with village cadres, and they don't want to help me. (Ying Y.F., villager, male, 45 years old)

However, there is also reason to believe that the shame of poverty and the stigma of claiming benefits has increased substantially in China in recent years. As Lister, (2004, p. 101) observed, 'contemporary discourses of poverty are rooted in history'. However, whereas, in the past, poverty was more or less the norm and acceptance of it fatalistic, now it is more exceptional and attributed to individual failure. In the early days of the People's Republic, poverty was effectively universal and during much of the Maoist period poverty was even celebrated as a sacrifice made to lay the foundations for future prosperity. But now, with the tables turned and the majority of people becoming more prosperous, the minority is confronted with the accusation and challenge: 'Why didn't you escape poverty?'

To be poor is not shameful when we are all poor. More than 20 years ago, most families could not make ends meets. Village cadres were as poor as us. No one could laugh at others because everyone faced the same difficulties ... . But the situation has changed now; most of the families are not worried about food and other needs. Many new houses have been constructed in the past ten years in our village. Poor families become fewer and fewer. And I think that the poor should reflect on themselves first. (Wang D.H., villager, male, 64 years old)

In the pre-reform period, political identity was the basis of a social stratification system founded on public ownership, communist ideology and substantial redistribution (Li, Q., 1997; Li, L. L., 2003). People in poverty were accorded high political status as representatives of the proletariat, whereas the rich were to be punished. In the countryside, the official categorisation prioritised low- and medium-income peasants and excluded landlords and rich peasants from collective policies. While material circumstances were extremely harsh, people in poverty appeared largely to have avoided stigma (Ci, 2013).

With the market-oriented reforms and reduced redistribution, economic status has replaced political status as the basis of social stratification (Szeleny \& Kostell, 1996; Walder, 
1996). Even so, it is important to recognise that, in the process of reform, political capital has often translated directly into higher incomes and economic power, while 'guanxi' remains an active ingredient in the distribution of influence and resources. Nevertheless, poverty is no longer seen in a positive light (Li, L. L., 2003), but has become a source of shame:

In modern society ... you are successful if you earn lots of money, no matter how you earn it. You are a loser if you cannot earn money. I am a loser because I am poor. (Hu J., villager, male, 43 years old)

\section{Conclusion}

Internationally, the take-up of social assistance is typically low, and lower than for other benefits (Finn \& Goodship, 2014; Oorschot, 2006). The reasons are complex but include the stigma that generally attaches to receipt (Baumberg, 2016; Gubrium et al., 2013). However, in China claims for social assistance are very high, albeit the demand appears to be from people who, though ostensibly ineligible, are nevertheless awarded benefits. The reason for this has previously been linked to corruption and to the exploitation of dibao for purposes of rural governance (Li \& Li, 2015; Li \& Walker, 2016). While acknowledging both mechanisms, this study explored the moral reasoning underpinning the claims made by ineligible recipients and the under-consumption by eligible non-recipients (see Figure 1). The stigma that usually serves to deter illicit claims is much weakened in rural China by culture and history. Some view dibao, not as a scheme solely for people in poverty, but as a community benefit akin to those that were operative when villages were organised as collectives. Dibao is further separated from poverty in the public mind by the multiple purposes to which it is put by village cadre. Indeed, receipt of dibao is sometimes seen as demonstrable evidence of having influence with the village cadre.

However, with poverty comes lack of influence, social invisibility, political impotence, shame and stigma. In the Maoist era, poverty was portrayed as a virtue rewarded by political status and positive redistribution. But with marketisation, poverty, as elsewhere in the world, is presented as the epitome of personal failure dissociated from structural or political causes (Walker, 2014). Without recourse to 'guanxi', people in poverty can receive dibao only if neighbours publically testify that they are destitute. Such is their lowly social status that they often do not expect to be awarded dibao.

Anti-poverty in China, responding to negative critique, is currently focused on improved targeting with a new recipient database, improved monitoring and better administration framed as part of the 'fighting corruption' agenda. But to date, policy has largely ignored local culture, the increasing 'shame of poverty' and the declining 'shame of injustice' that helps to explain the poor targeting of dibao.

The Chinese experience offers a salutary warning of the dangers of implementing a social assistance system nominally based on rights without the political, legal and cultural infrastructure to support it. Focusing on the incompatibilities between culture and policy, it is necessary to alter implementation to meet cultural requirements and/or to strengthen administration to weaken the influence of the local culture. Seeking to rid dibao of stigma by challenging negative rhetoric and removing procedures that create or exploit public shaming needs to be accompanied by measures to promote and support the rights enshrined in national 
legislation. Often in the global North, such goals have been achieved through the professionalisation of assessment procedures and an enhanced role for social work, but in much of the developing world, including China, the advance of social work has been limited. Therefore, an alternative might be to strengthen supervision of the administration to weaken cultural influences, while simultaneously seeking to avoid the 'elite capture' that currently characterises dibao by means of transparent decision making, clear accountability and robust procedures for redressing grievances.

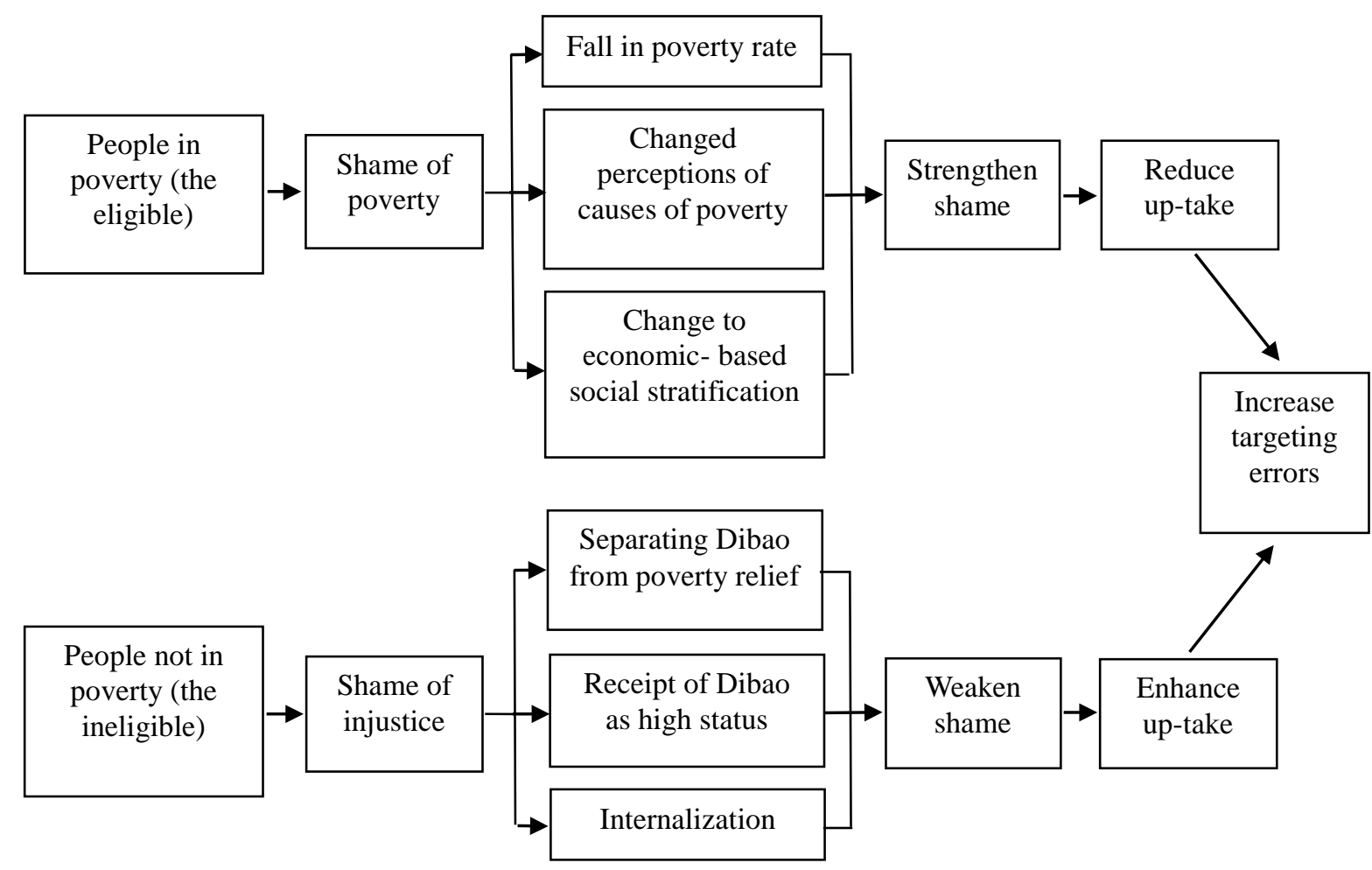

Figure 1. Strengthened/weakened shame and the take-up of Dibao. 


\section{References}

Baumberg, B. (2016). The stigma of claiming benefits: A quantitative study. Journal of Social Policy, 45(1), 181-200.

Baumberg, B., Bell, K., \& Gaffney, D. (2012). Benefits stigma in Britain. London: Turn2Us.

Bedford, O. \& Hwang, K. K. (2003). Guilt and shame in Chinese culture: A cross-cultural framework from the perspective of morality and identity. Journal for the Theory of Social Behaviour, 33(2), 127-144.

Bu, C. (2003). Theory of “Difference Order Pattern” and its modern meaning. Sociological Research, 1, 21-29. (In Chinese)

Ci, J. W. (2013). Agency and other shakes of poverty. The Journal of Political Philosophy, 21(2), 125-150.

Cui, S. Y., Liu, C. L., \& Song, Y. X. (2009). A survey and analysis of consummating rural minimal living security. Shangdong Social Sciences, 3, 58-61. (In Chinese)

Daigneault, P.-M., Jacob, S., \& Tereraho, M. (2012). Understanding and improving the take-up of public programs: Lessons learned from the Canadian and international experience in human services. International Journal of Business and Social Science, 3(1), 39-50.

Dorsett, R. \& Heady., C. (1991). The take-up of means-tested benefits by working families with children. Fiscal Studies, 12(4), 22-32.

Fei, X. (1992). From the soil. Berkeley: University of California Press.

Ferguson, C. (1999). Global social policy principles: Human rights and social justice. London: DfID.

Finn, D. \& Goodship, J. (2014). Take-up of benefits and poverty: An evidence and policy review. London: Inclusion.

Geng, Y. (2012). Disordered distribution: Current practices of rural lowest living guarantee. Population and Development, 18(1), 68-73. (In Chinese)

Golan, J., Sicular T., \& Umapathi, N. (2014). Any guarantees? China's rural minimum living standard guarantee program. Washington: World Bank, Social Protection and Labor, Discussion Paper 1423.

Gold, T. B. (1985). After comradeship: Personal relations in China since the cultural revolution. The China Quarterly, 104 (Dec.), 657-675.

Gubrium, E., Pellissery, S., \& Lødemel, I. (2013). The shame of it: Global perspectives on anti-poverty policies. Bristol: Policy Press.

Hernanz, V., Malherbert, F., \& Pellizzari, M. (2004). Take-up of welfare benefits in OECD countries: A review of the evidence. Paris: OECD Social, Employment and Migration Working Papers No. 17.

Jo, Y. N. (2013). Psycho-social dimensions of poverty: When poverty becomes shameful. Critical Social Policy, 33(3), 514-31.

Jordan, B. (1996). A theory of poverty and social exclusion. Cambridge: Polity Press.

Kerr, S. (1982). Deciding about supplementary pensions. Journal of Social Policy, 11(4), $505-517$.

Leisering, L. \& Leibfried, S. (1999). Time and poverty in western welfare states. Cambridge: Cambridge University Press. 
Li, K. (2012). Normative disorder and value disintegration: A research on rural minimal living security in the village context. Journal of Jinyang, 3, 48-53. (In Chinese)

Li, L. L. (2003). The transformation of institutions and changes of social stratification. Sociological Research, 5, 42-51. (In Chinese)

Li, Q. (1997). Political stratification and economic stratification. Sociological Research, 4, 32-41. (In Chinese)

Li, M. \& Walker, R. (2016, in press). Targeting Social Assistance: Dibao and Institutional Alienation in Rural China. Social Policy and Administration.

Li, Y. S. \& Li, Q. R. (2015). Checking institutions of rural Dibao families' economic status. Social Sciences Research, 3, 106-114. (In Chinese)

Lister, R. (2004). Poverty. Cambridge: Polity Press.

Liu, Q. (2009). Targeting errors and regulations for the practice of rural Dibao. Survey's World, 6, 40-41. (In Chinese)

Merriam, S. (2014) Qualitative research: A Guide to design and implementation (3rd ed.). San Francisco: Sage.

Oorschot, van W. (2006). Making the difference in social Europe: Deservingness perceptions among citizens of European welfare states. Journal of European social policy, 16(1), 2342.

Pogge, T. (2002). World poverty and human rights. Cambridge: Polity Press.

Qi, J. C. (1985). Communism and clientelism: Rural politics in China. World Politics, 37(2), 238-266.

Ritchie, J. (1988). Income related benefits: The causes of non take-up. London: SCPR.

Ritchie, J., Lewis, C., McNaughton Nicholls, C., \& Ormston, R. (2014) Qualitative research practice. London: Sage.

Ridge, T. (2002). Childhood poverty and social exclusion. Bristol: Policy Press.

Seawright, J. \& Gerring, J. (2008). Case selection techniques in case study research: A menu of qualitative and quantitative options. Political Research Quarterly, 61, 294-308.

Sen, A. (1999). Development as freedom. Oxford: Oxford University Press.

Sun, L. P. (1996). 'Relationship', social relationship and social structure. Sociological Research, 5, 20-30. (In Chinese)

Szelenyi, I. \& Kostello, E. (1996). The market transition debate: Toward a synthesis. American Journal of Sociology, 101(4), 1082-1096.

Vogel, B. F. (1965). From friendship to comradeship. China Quarterly, 21(Jan.-Mar.), 46-60.

Walder, A. (1996). Markets and inequality in transitional economies: Toward testable theories. American Journal of Sociology, 101(4), 1060-1073.

Walker, R. (2005). Social Security and Welfare: Concepts and comparisons. Milton Keynes: Open University Press/McGraw-Hill.

Walker, R. (2014). The Shame of Poverty. Oxford: Oxford University Press.

Wu, J. M. (2009). Rule-socialization and rule-flexibility: Empirical research on governmental relief. Journal of Public Management, 6(4), 18-24. (In Chinese)

Zhu, M. (2011). The reasons for “moral risk” of villagers' committee in rural Dibao and its avoiding strategies. Rural Economy, 5, 109-112. (In Chinese)

Zhu, W. (2012). Strictly oppose unhealthy practices in urban and rural Dibao. Renminwang, May 29. Retrieved 8 April 2013 from 
http://news.xinmin.cn/rollnews/2012/05/29/14933396.html (In Chinese) 